\title{
Study of ANC and immediate PNC mothers admitted with severe anemia in GMC Chandrapur
}

\author{
V Shrirame D. ${ }^{1 *}$, Waikar M. ${ }^{2}$ \\ DOI: https://doi.org/10.17511/ijmrr.2021.i01.06 \\ 1* Deepti V Shrirame, Assistant Professor, Department of Obstetrics and Gynecology, Chandrapur, Maharashtra, India. \\ 2 M.R. Waikar, Professor and HOD, Department of Obstetrics and Gynecology, Chandrapur, Maharashtra, India.
}

\begin{abstract}
Maternal mortality continues to be a major health problem in the developing world. About $20 \%$ of cases of maternal mortality are due to anemia (preventable cause). Objectives: 1 . To define the geographical areas around Chandrapur from where the cases of anemia are referred. 2. To co-relate variables like maternal age, gestational age, parity and the time elapsed between last childbirth and current pregnancy. Materials and Methods: $\mathrm{Hb}$ of ANC and immediate PNC patients referred with severe anemia was estimated with Sahli's Haemoglobinometer. Inclusion criteria: 257 ANC and immediate postpartum patients admitted between July 2016 to September 2016 with severe anemia and transfused with blood. Exclusion criteria: anemia due to acute blood loss.Results: $77.8 \%$ severe anemia cases were between 21 to 30 years. $22 \%$ were from Chandrapur taluka.12.8\%cases from Rajura and $10.12 \%$ from Korpana taluka,68.26\% cases had gestational age more than 28 weeks.59.92\%cases were multipara. In $84.42 \%$ of cases last childbirth was less than 3 years. $20 \%$ cases were of sickle cell anemia patients. There were no cases of abruption placentae, surgical wound infection and maternal mortality. No patient had postpartum haemorrhage as were managed with active management of the third stage of labour and prophylactic 3 tablets of misoprostol per rectum. There were 12 preterm deliveries with no intrauterine deaths. Conclusion: Peripheral preventive services must be strengthened on a priority basis in Chandrapur, Ballarpur, Rajura and Korpana talukas which belong to south Chandrapur where the tribal area is predominant. Probable causes in these areas might be related to culture, ignorance, dietary habits and availability of medical staff which needs to be addressed. Effective counselling regarding early registration, restriction of parity, contraception for spacing births, diet and iron and folic acid supplementation is essential for preventing anemia.
\end{abstract}

Keywords: Severe anemia, Maternal mortality, ANC, PNC

\section{Corresponding Author}

Deepti V Shrirame, Assistant Professor, Department of Obstetrics and Gynecology, Chandrapur, Maharashtra, India. Email: drdeeptivs@gmail.com

\section{How to Cite this Article}

Shrirame DV, Waikar MR. Study of ANC and immediate PNC mothers admitted with severe anemia in GMC Chandrapur. Int J Med Res Rev. $2021 ; 9(1): 41-45$.

Available From

https://ijmrr.medresearch.in/index.php/ijmrr/article/ view/1242
To Browse

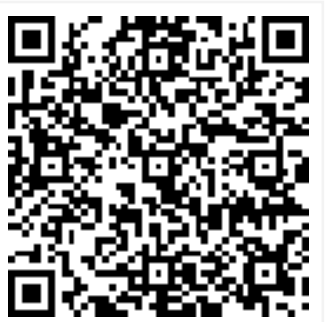

Manuscript Received 2021-01-05

Conflict of Interest No
Review Round 1 2021-01-15

Funding

Nil
Review Round 2

2021-01-25

Ethical Approval Yes
Review Round 3

Plagiarism X-checker $6 \%$
Accepted 2021-02-22

(C) 2021 by Deepti V Shrirame, M.R. Waikar and Published by Siddharth Health Research and Social Welfare Society. This is an Open Access article licensed under a Creative Commons Attribution 4.0 International License https://creativecommons.org/licenses/by/4.0/ unported [CC BY 4.0]. 


\section{Introduction}

Maternal mortality continues to be a major health problem in the developing world. Nearly 600,000 women die each year as a result of complications of pregnancy and childbirth; most of these deaths could be prevented with attainable resources and skills(WHO 2003). (1,2,4).

The most common direct causes for maternal mortality include hemorrhage(25\%), hypertensive disorders of pregnancy $(12 \%)$, complications from unsafe abortion(13\%), sepsis(15\%), obstructed labor $(8 \%)$, indirect causes include viral hepatitis ,malaria, anemia, HIV/AIDS \& cardiovascular disease. $20 \%$ cases of maternal mortality are due to anemia (preventable cause) $(1,2,3)$.

It causes direct and indirect deaths from cardiac failure, haemorrhage, infection and preeclampsia $(1,2,3)$. Anemia also increases perinatal morbidity and mortality rates due to an increase in preterm births and IUGR, which also been found to cause low iron stores, iron deficiency anemia and cognitive and behavioural dysfunction in infants. Therefore, according to the UN declaration of 1997, anemia is a major public health problem that needs total elimination.

The risk of Maternal mortality decreases by about $20 \%$ for each $1 \mathrm{~g} / \mathrm{dl}$ increase in haemoglobin. The two most common causes of anemia during pregnancy and immediate puerperium are IDA and Acute Blood Loss (1). The body does not have enough healthy red blood cells to bring oxygen to body tissues and hence the various complications.

\section{SYMPTOMS AND SIGNS OF ANEMIA}

SYMPTOMS: It includes the feeling of weakness, lassitude, indigestion, loss of appetite, poor work performance, palpitations, dyspnoea, giddiness, enema, breathlessness

SIGNS: pallor, glossitis, stomatitis, oedema, tachycardia, soft systolic murmur and rarely generalised anasarca and even CCF.

\section{Aims and Objectives}

- To define geographical areas around Chandrapur from where the cases of anemia are referred.

- To co-relate variables like Maternal age, Gestational age, Parity, the time elapsed between last childbirth and current pregnancy

\section{Material and Methods}

$\mathrm{Hb}$ of ANC and immediate PNC patients referred with severe anemia was estimated with Sahil's Haemoglobinometer.

Setting: The study was conducted in the GMC Chandrapur, Department of Obstetrics and Gynaecology, maternity ward.

Duration and type of study: 3 months study from July to September 2016, descriptive record-based study.

Sampling method: cases were selected by universal sampling. Sample size calculation:257 ANC and PNC patients.

The data collection procedure was documents and records. Descriptive statistics were calculated with percentages.

- Inclusion criteria:257 ANC and immediate postpartum patients admitted between July 16 to September 2016 with severe anemia and transfused with blood.

- Exclusion criteria: Patients having anemia due to acute blood loss, moderate anemia or no anemia.

\section{Results}

$77.8 \%$ severe anaemia cases were in the age group of 21 to 30 years, $15.56 \%$ cases were less than 21 years and $6.62 \%$ cases where more than 30 years $.22 \%$ cases were from Chandrapur Taluka, $12.8 \%$ Rajura $810.12 \%$ Korpana Taluka. $68.29 \%$ cases were in the gest age more than 28 weeks whereas $31.71 \%$ cases were having gestational age less than 28 weeks.

$40.08 \%$ cases were primigravida whereas $59.92 \%$ cases were multipara out of which $18.29 \%$ had parity equal to or more than $3.84 .42 \%$ LCB $<3$ years. 20 cases were of sickle cell anemia patients which accounted for around $8 \%$ of severe anemia cases. 55 cases had a normal delivery, 12 cases had preterm delivery whereas 18 patients were subjected to caesarean section.

There was no case of abruptio placentae, intrauterine deaths, surgical wound infection and maternal mortality. No patient had postpartum haemorrhage as were managed with active management of the third stage of labour and prophylactic 3 tablets of misoprost per rectum. 
Table-1: Taluka wise and Age-wise distribution of severe anemia.

\begin{tabular}{|c|c|c|c|}
\hline \multirow[t]{2}{*}{ Taluka } & \multicolumn{3}{|c|}{ Age wise $\mathrm{Hb} \%$ <=7gm } \\
\hline & $<=21$ & $>21-<=30$ & $>30$ \\
\hline Ballarpur & 3 & 21 & 1 \\
\hline Bhadravati & 0 & 7 & 4 \\
\hline Brahmapuri & 0 & 1 & 0 \\
\hline Chandrapur & 4 & 47 & 6 \\
\hline Chimur & 3 & 6 & 0 \\
\hline Gadchandur & 0 & 1 & 0 \\
\hline Gondpipari & 2 & 6 & 0 \\
\hline Jivati & 6 & 5 & 0 \\
\hline Korpana & 6 & 18 & 2 \\
\hline Mul & 2 & 7 & 0 \\
\hline Nagbhir & 0 & 10 & 0 \\
\hline Poumbhurna & 0 & 3 & 0 \\
\hline Rajura & 2 & 28 & 3 \\
\hline Savali & 0 & 2 & 0 \\
\hline Sindewahi & 2 & 10 & 0 \\
\hline Visapur & 0 & 0 & 0 \\
\hline Warora & 3 & 5 & 0 \\
\hline Gadchiroli & 2 & 2 & 0 \\
\hline Yavatmal & 5 & 18 & 0 \\
\hline Adilabad & 0 & 2 & 1 \\
\hline Asifabad & 0 & 1 & 0 \\
\hline
\end{tabular}

\section{Table-2: Age Distribution}

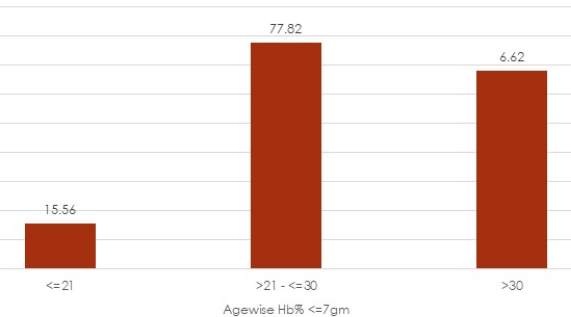

Maximum patients were observed in 21-30 years age group.

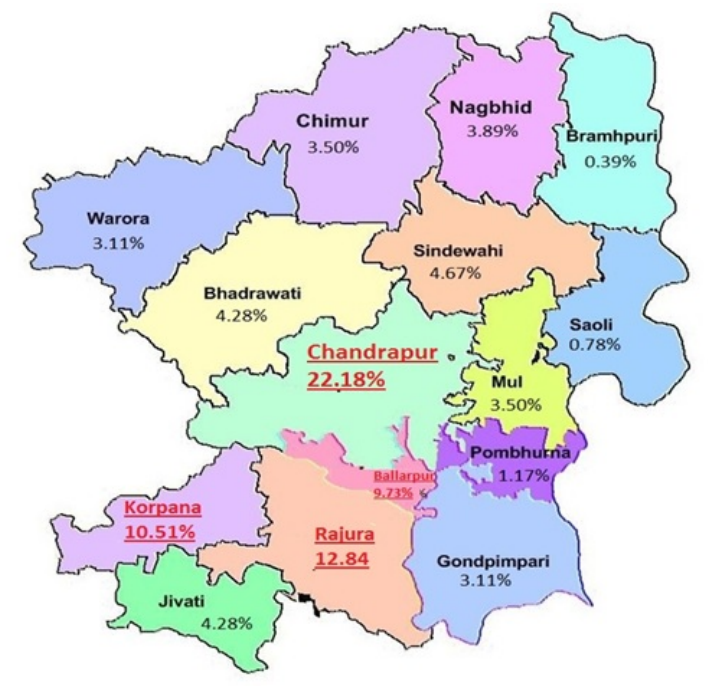

Fig-1: Taluka Wise \% Of Severe Anemia Cases

Table-3: Gestational age of Prergnancy.

\begin{tabular}{|c|l|l|}
\hline Hb\% & \multicolumn{1}{|c|}{ Gestation <=28 Weeks } & \multicolumn{1}{|c|}{ Gestation > 28 Weeks } \\
\hline$<=7 \mathrm{gm}$ & 82 & 175 \\
\hline
\end{tabular}

$\%$ of Severe Anemia Cases According to Gestational Age

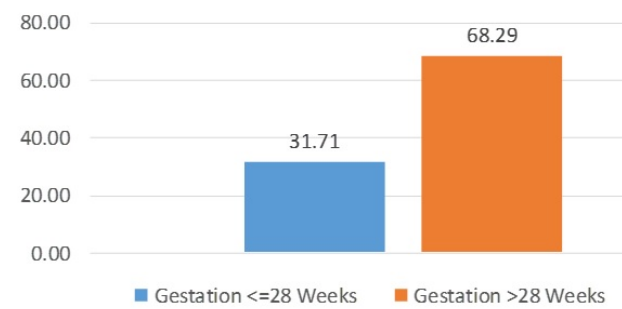

Fig 2: Distribution as per gestational age.

Most of the cases were having gestational age of more than 28 weeks. It means anemia prevalence increases with the advancement in gestational age.

Table-4: Parity

\begin{tabular}{|l|l|l|l|}
\hline & \multicolumn{1}{|c|}{ Primi } & \multicolumn{1}{c|}{ G2 } & G3 \& More \\
\hline$<=7 \mathrm{gm}$ & 103 & 107 & 47 \\
\hline
\end{tabular}

The most case was having parity of 1 or 2 with almost 40 per cent each.

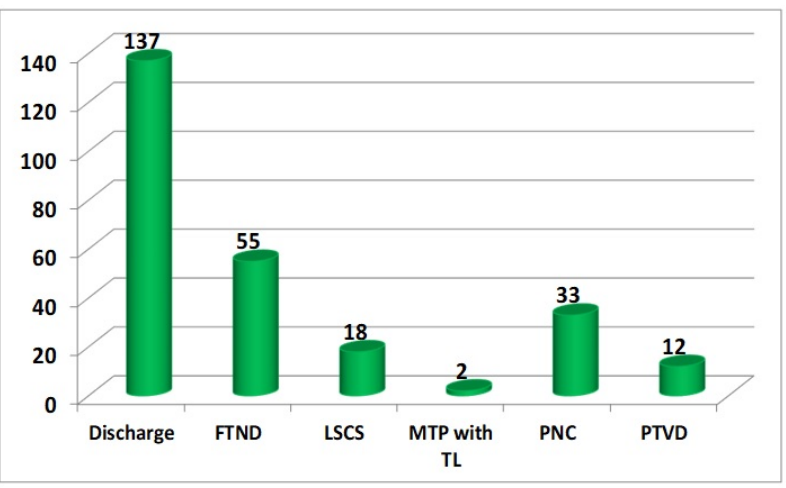

Fig-3: Outcome of anemia cases.

\section{Discussion}

In our study there was no maternal death similar to the study conducted by Ravishankar Suryanarayan et al. [5] Rukuni et al [13] study had maternal In our study, there were $14 \%$ preterm deliveries whereas Marahatta [7] in Nepal reported 3\% preterm deliveries in anaemic women and Ravishankar Suryanarayan et al [5] had no preterm deliveries. Rohilla $M$ et al [11] had in their study $5.12 \%$ preterm deliveries, abruption $3.12 \%, \mathrm{PPH}$ in $25.5 \%$ Nair $M$ et al [12] had in their study $3.3 \%$ cases of PPH. 
In the study conducted by Rukuni R et al (13), APH cases in anemia patients were $14.14 \%$ and $\mathrm{PPH}$ cases in anemia patients were $21.78 \%$, maternal deaths were $0.01 \%$. In our study, there was no case of abruption or PPH.

In our study around $60 \%$ of severe anemia cases were multipara similar to the study by Ravishankar Suryanarayan et al [5], Obese et al [14] and Hashim $\mathrm{N}$ et al. [8] In our study around $78 \%$ of cases of severe anemia were between the age group of 21 to 30 years similar to the study by Hashim et al (8). Around $68 \%$ of cases of severe anemia had gestational age more than 28 weeks similar to the study by Hashim $\mathrm{N}$ et al (8).

Strength of our study which adds to existing knowledge. We could identify the talukas in Chandrapur district where the prevalence of severe anemia in pregnant and postpartum women is high which needs to be addressed at different levels.

\section{Limitations}

- The short duration of the study

- Long term effects of anaemia, i.e. secondary haemorrhage, subinvolution, sepsis in mother and prognosis of preterm or IUGR babies in the late neonatal period or infancy could not be assessed.

\section{Conclusion}

Peripheral preventive services must be strengthened on a priority basis in Chandrapur, Ballarpur, Rajura and Korpana talukas which belong to south Chandrapur where the tribal area is predominant. Probable problems in these areas might be related to culture, ignorance, dietary habits \& availability of Medical Staff which need to be addressed.

\section{What does the study add to the existing knowledge?}

Effective counselling regarding early registration restriction of parity contraception for spacing births diet and iron and folic acid supplementation is essential for preventing anemia.

\section{Author's contribution}

Dr. Deepti V Shrirame: Concept, study design

Dr. M.R. Waikar: Manuscript preparation

\section{Reference}

01. DC Dutta. Medical and Surgical Illness Complicating Pregnancy. Haematological Disorders in DC Dutta's Textbook of obstetrics Hiralal Konar. 2015;20;303-319.

[Crossref]

02. KOSCHORKE A, Egbor $M$, Bhide A. Haematological Disorders and Red-Cell Alloimmunization in Pregnancy. Arias' Practical Guide to High-Risk Pregnancy and Delivery- A South Asian Perspective. 2015;233.

[Crossref]

03. WHO. Managing complications in pregnancy and childbirth- A guide for midwives and doctors, Integrated management of pregnancy and childbirth(Draft Document). WHO. 2000. [Crossref]

04. WHO. Pregnancy, childbirth, postpartum and newborn care- A guide for essential practice. Geneva-WHO. 2003.

[Crossref]

05. Suryanarayana R, Chandrappa M, Santhuram AN, Prathima S, Sheela SR. Prospective study on prevalence of anemia of pregnant women and its outcome- A community based study. Journal of family medicine and primary care. 2017;6(4)739.

doi: $10.4103 /$ jfmpc.jfmpc3317 [Crossref]

06. De Benoist B, Mc Lean E, Egli I, Cogswell M. Worldwide Prevalence of anemia19932005:WHO Global Database on Anemia. Geneva- World Health Organiszation. 2008. [Crossref]

07. Marahatta R. Study of anaemia in pregnancy and its outcome in Nepal Medical College Teaching Hospital, Kathmandu, Nepal. Nepal Medical College journal- NMCJ. 2007;9(4)270-4. [Crossref]

08. Hashim N, Farooqi M, Naqvi S, Jaffery HF. Anemia; moderate to severe during pregnancy. Professional Med J. 2014;21(2)247-252. [Crossref]

09. Kalaivani K. Prevalence and consequences of anemia in pregnancy. Indian Jmed Res. -33. [Crossref] 
10. Ivan EA, Mangaiarkkarasi A. Evaluation of anemia in booked antenatal mothers during the last trimester. J Clin Diagn Res. 2013;7;248790.

doi: $10.7860 / J C D R / 2013 / 6370.3586 \quad$ [Crossref]

11. Rohilla M, Raveendram A, Dhaliwal LK, Chopra S. Severe anemia in pregnancy- A tertiary hospital experience from northern India. J Obstet Gynaecol. 2010;30(7);694-6.

doi: 10.3109/01443615.2010509821 [Crossref]

12. Nair M, Choudhary MK, Choudhary SS, Kakoty SD, Sarma UC, Webster $P$, et al. Association between maternal anaemia and pregnancy outcomes- A cohort study in Assam, India. BMJ Glob Health. 2016; 1 ; e000026.

doi: $10.1136 /$ bmjgh-2015-000026 [Crossref]
13. Rukuni R, Bhattacharya S, Murphy MF, Roberts D, Stanworth SJ. Knight $M$ Maternal and neonatal outcome of antenatal anemia in a Scottish population- a retrospective cohort study. Acta Obstet Gynecol Scand. 2016;95;555-564.

doi: 10.1111/aogs.12862 [Crossref]

14. Obse N, Mossie A, Gobena T. Magnitude of anaemia and associated risk factors among pregnant women attending antenatal care in Shalla Woreda, West Arsi Zone, Oromia Region, Ethiopia. Ethiop J Health Sci. 2013;23;165-73. [Crossref] 